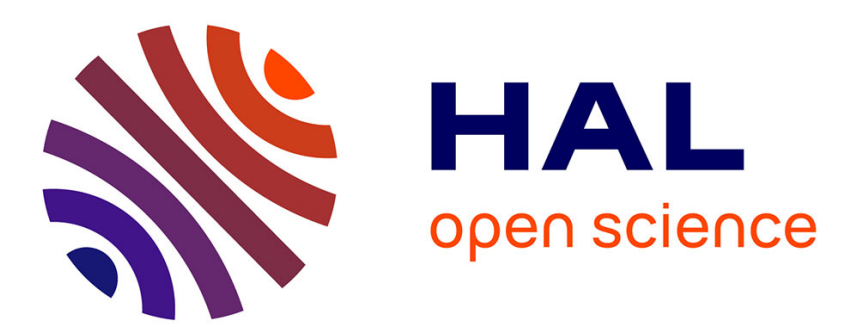

\title{
Fostering collaborative meta-value chain practices
}

Raul Rodriguez Rodriguez, Angel Ortiz, Juan Jose Alfaro

\section{To cite this version:}

Raul Rodriguez Rodriguez, Angel Ortiz, Juan Jose Alfaro. Fostering collaborative meta-value chain practices. International Journal of Computer Integrated Manufacturing, 2009, 22 (05), pp.385-394. 10.1080/09511920802389546 . hal-00513409

\section{HAL Id: hal-00513409 \\ https://hal.science/hal-00513409}

Submitted on 1 Sep 2010

HAL is a multi-disciplinary open access archive for the deposit and dissemination of scientific research documents, whether they are published or not. The documents may come from teaching and research institutions in France or abroad, or from public or private research centers.
L'archive ouverte pluridisciplinaire HAL, est destinée au dépôt et à la diffusion de documents scientifiques de niveau recherche, publiés ou non, émanant des établissements d'enseignement et de recherche français ou étrangers, des laboratoires publics ou privés. 


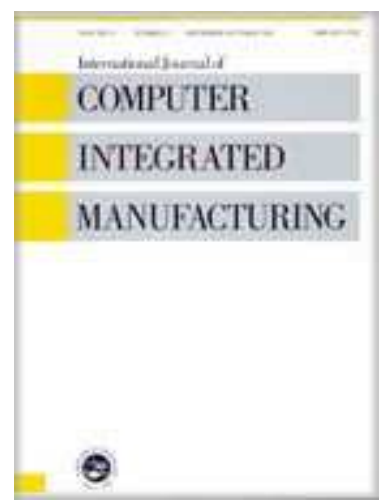

\section{Fostering collaborative meta-value chain practices}

\begin{tabular}{|c|c|}
\hline Journal: & International Journal of Computer Integrated Manufacturing \\
\hline Manuscript ID: & TCIM-2007-IJCIM-0120.R3 \\
\hline Manuscript Type: & Original Manuscript \\
\hline $\begin{array}{l}\text { Date Submitted by the } \\
\text { Author: }\end{array}$ & 29-Jul-2008 \\
\hline Complete List of Authors: & $\begin{array}{l}\text { Rodriguez Rodriguez, Raul; Polytechnic University of Valencia, } \\
\text { Enterprises Management } \\
\text { Ortiz, Angel } \\
\text { Alfaro, Juan Jose }\end{array}$ \\
\hline Keywords: & $\begin{array}{l}\text { INFORMATION SYSTEMS, SUPPLY CHAIN MANAGEMENT, } \\
\text { OPERATIONS MANAGEMENT, COLLABORATIVE MANUFACTURING }\end{array}$ \\
\hline Keywords (user): & Meta-value chain, collaboration \\
\hline
\end{tabular}

\section{今) ScholaroNE" \\ Manuscript Central}




\title{
Fostering Collaborative Meta-value Chain Practices
}

\author{
R. R. Rodriguez ${ }^{\mathrm{a} 1}$, A. Ortiz ${ }^{\mathrm{b}}$, J. J. Alfaro $^{\mathrm{c}}$ \\ ${ }^{a, b, c}$ Department of Enterprises Management, Polytechnic University of Valencia, Valencia, \\ Spain.
}

\begin{abstract}
This paper presents the main advantages of creating a meta-value chain, as a source of sustainable competitive advantage in today's markets. This is not an easy task, as complete collaboration between the enterprises forming the value-chain as well as a proper interaction of the collaborative and technological processes must take place. The final objective of offering to customers an extended value proposition is enabled by the development of different products that implies collaborative practices between the members of the meta-value chain. Such products will be defined regarding the main collaborative processes to be potent within the meta-value chain and supported by technological tools and architecture that will enable the necessary informational flows between the members under different formats. Finally, a meta- value chain is presented, as well as the main results - benefits, drawbacks and possible future actions- and recommendations for creating a meta-value chain.
\end{abstract}

Keywords: Meta-value chain; collaboration; extended value proposition.

\section{Introduction}

Globalisation and worldwide competitiveness have promoted the creation and consolidation of the so-called Extended Enterprises (EE), which transcend the single enterprise domain and build meta-enterprises.

Most existing EE have initially focused on reinforcing the links and flows between companies that are involved in the same value chain. However, recently, the phenomenon has shifted toward the creation of EE that cross the barriers of a single value chain, and link different complementary value chains building a meta-value chain. Many industrial companies have wanted to or have been selling and distributing jointly their aggregated products for a long time and now they face the challenge of the complete integration of their value chains (Putnik and Cunha, 2007).

The starting point of any meta-value chain winning approach is consequently collaboration, where the concept inherently implies agility and learn to learn capacity (Christopher, 2003). Within a value chain, the downstream supply chain, hereinafter called selling chain, plays a key role to build and deliver competitive value propositions to customers, as it represents the direct nexus between the value chain and the customer (Seuring, 2006). The selling chain focuses on the management of orders life cycle, from the initial order placement to the delivery and provision of physical goods, covering the part of the value chain that goes from manufacturers to

\footnotetext{
${ }^{1}$ Corresponding author. Email: raurodro@upvnet.upv.es
} 
end customers (including logistics platforms/operators, distribution, intermediaries, resellers and retailers). Similarly, the meta-selling chain, defined as the aggregation of selling chains within a meta-value chain, becomes a key player to build and deliver competitive extended value proposition to customers.

In order to build a successful meta-value chain, collaboration must be achieved at three levels (see Figure 1):

The company domain; the focus is put here on each single enterprise within the

- $\quad \mathrm{EE}$ and leads to the collaborative enterprise

- The supply chain domain; the focus is put here on each selling chain within the EE and leads to the collaborative selling chain.

- The meta-value chain domain; the focus is put here on the set of selling chains within the EE and leads to the extended collaborative selling chain.

(Figure 1)

While industrial companies have learnt to establish added-value relationships and flows with their supply chain partners, when they now face the new challenge of building relationships with other value chains, they suffer from the lack of existing know-how and expertise in meta-value chain operation and management, (including methodologies, reference models, case studies, best practices, and business \& ICT solution maps) (Cingil and Dogac, 2001; Kim et al. 2006).

A recent trend in meta-enterprises has begun to transform their traditional masterslave win- lose/lose-win business relationship models into fully peer-to-peer win-win ones (Molina and Wright, 2005; Busi and Bititci, 2006; Alfaro et al. 2007; Derrouiche et al. 2008). The same collaborative model is required for meta-value chains.

The creation of a successful meta-value chain is indeed a complex and risky endeavour that implies a major transformation for a set of industrial companies, especially in terms of dependency of another value chain, cross-enterprise and crossvalue chain culture, market strategy, business processes and models, production and demand planning, logistics, and integration of materials/management/decision/ knowledge flows (Lee et al. 2006).

Many authors (Raghunathan, 1999; Deek et al. 2003; Shang et al. 2003; Akkermans, 2004; Bititci et al. 2005; Petersen et al. 2005; Pappas et al. 2006; Sohn, and Lim, 2008) have presented the main advantages of maintaining supply chain collaborative practices whereas there is not that much research done yet that point out the advantages of meta-value chain practices. According to some works (Prasad and Sounderpandian, 2003), (Rupp and Ristic, 2004), (Fairchild, 2005), (Seuring, 2006), (Ketchen and Hult, 2007), it is possible to affirm that there are several benefits to be achieved from meta- value chain practices such as i) higher value added to customers, in terms of improved value proposition by offering an Extended Value Proposition, which will allow customers to have available a combination of products/services that 
will meet and even overcome their expectations and needs; ii) enhancement of overall competitiveness, as enterprises will be able to provide differentiated products/services respect to other. This is specially true in low cost in low cost focused enterprises, which will therefore achieve competitive advantages and foster their innovation capabilities as well as to gain knowledge of competing in present and future market conditions with the inter-value chains collaborative practices; iii) Cross-country and inter-value chains interchanges, building worldwide networked enterprises and value chains within a meta-value chain context, which is supported by dynamic relationships schemas and innovative cooperation and coordination business paradigms; iv) derived from the latter, cost reduction, optimisation of materials, wastes and energy consumption at both the intra-enterprise and value chain level. Additionally, better coordination and cooperation practices should lead to detect inefficiencies of processes, stocks, material and information and more rational production plans. In general, supply chains forming a meta-value chain are considered as best value supply chains compared to traditional supply chains (Ketchen and Hult, 2007).

Additionally, some authors (Prasad and Sounderpandian, 2003), (Fairchild, 2005), (Kim et al. 2006), (Ketchen and Hult, 2007), (Gunasekaran et al. 2008) have pointed out some of the main challenges that meta-value chain practices should still overcome. Then, there is a need of following an integral approach when designing a meta-value chain, as efforts are usually put on covering very particular operations or services instead of offering an integrated approach able to provide a true competitive meta-value chain strategy as a response to a networked and global economy (Prasad and Sounderpandian, 2003), (Gunasekaran et al. 2008). Moreover, there is a need to design the meta-value in a way it can react to business environment changes and cope with fast changing markets.

To achieve these objectives and be able to meet the presented challenges, new business models and processes need to be developed between companies involved in a meta-value chain.

Therefore, it is necessary to reengineer the selling chain of the different collaborative value chains in order to offer to the final consumer new added value packaged products and services. These will provide the company with a competitive advantage and the end customer with an extended value proposition, through the collaboration among extended selling chains.

This paper presents the main products that foster the creation and maintenance of a meta-value chain, as well as the technological architecture that supports such collaborative practices. Additionally, the main results obtained of applying these collaborative practices to one industry meta-value chain are also presented. It also highlights how this work has helped to overcome some of the challenges above introduced, and set some future research in this field.

\section{Methodology}

This work has been developed in the context of the EU project ECOSELL. Thus, this project aims to deliver an extended value proposition (EVP) to customers based on collaborative processes between several value chains, which together constitute a meta-value chain. When deciding what products would best support the creation and maintenance of a meta-value chain, a constructivist approach (Kasanen et al. 1993), 
(Coughlan and Coughlan, 2002) based on the following activities: recompilation, analysis and study of scientific knowledge, acquisition of main postulates and construction of an initial framework and election of supportive technological approaches, was followed. The initial elements considered were the following:

- The requirements and objectives that enterprises should accomplish to create and/or form part of a meta-value chain.

- The requirements that the products to be applied should cover to foster the creation and maintenance of a meta-value chain.

- The requirements already covered by existing scientific and technological frameworks in order to cover the needs identified in the two above points.

The completion of these tasks can provide the initial starting point for creating a meta-value chain. In the next points of the paper it will be shown the products chosen within the ECOSELL project context and associated relevant technological issues; then, the main results, benefits and drawbacks, achieved from a practical application of a meta-value chain are presented, highlighting lastly recommendations for those enterprises willing to form part of a successful meta-value chain.

\section{Creating and maintaining the meta-value chain}

In the creation of a meta-value chain, enterprises should be aware that the definition process might be broken down into two different environments: Design and Operation. The definition of the different tools, methodological and technical, needs to be carried out under these two environments. Then, it is necessary to carry out deep assessments and tools at both the business and the IT perspectives.

When deciding what products would best support the creation and maintenance of a meta-value chain, it is necessary to define what the main processes of such a metavalue chain are in order to successfully compete in the marketplace. In the ECOSELL project, enterprises agreed to focus on delivering an extended value proposition to final customers by offering a final pack of complementary products also called product pack (PP). Moreover, the meta-value chain was formed by three enterprises, a Spanish tiles manufacturer; an Italian glaze manufacturer; and an Italian furniture manufacturer. The glaze manufacturer was one of the tiles manufacturer's first tier suppliers, forming together one value chain. Such a value chain together with the one represented by the furniture manufacturer constituted the meta-value chain whose main purpose for delivering and extended value proposition to final customers was to offer a PP that included a combination of both tiles and furniture. Therefore, the main processes of this meta-value chain were related to downstream practices (selling chains) of the different value chains constituting the meta-value chain. Hence, Figure 2 shows these main processes.

(Figure 2)

It is necessary to point out that the enterprises forming the two value chains and, extensively, the meta-value chain of this work, had developed a previous strategic 
work together. Then, they had to agree what of their products/services could be suitable to form a pack of products attractive enough for customers. Once they were willing to collaborate they had to choose tiles and furniture that could be combined taking into account aesthetic, shape or manufacturability issues. As a result of this work they also decided what products would support their extended value proposition and what collaborative relationships they would follow. Their collaborative approach could be defined as "cooperative collaboration" (Cohen and Roussel, 2003), as they were able to share, not only transactional information, but also critical information on forecasts, inventory availability, purchase orders or order and delivery status.

Then, in order to enable the meta-value chain, the products to be created need to focus on these main processes that are: Demand, make, distribute and serve. In this case, the agreed products to be developed were five: 1) Collaborative Order Management; 2) Extended Distribution Management; 3) Collaborative Forecasting Management; 4) Extended Performance Management; 5) Collaborative Exception Management. These products are next presented and explained.

\subsection{Collaborative Order Management (COM)-Extended Distribution Management (EDM)}

The COM-EDM improves the traditional order management process providing support for complex cross-value chain orders with special focus on Available To Promise (check availability of products) /Capable To Promise (check capacity availability)/Distribution To Promise (check availability of transport) operations extended to the whole cross-value chain. The main idea is to provide customers not only with the possibility of ordering a PP but also to configure key parameters to perceive an extended value proposition such as type of products, quantity, delivery date, delivery place/location, and other factors such as installation capacity. A customer should be able to order a PP made out of complementary products offered by organisations forming the meta-value chain; state a delivery date for such a product pack; to obtain in real time an answer from the meta-value chain. Then, organisations forming the meta-value chain must collaborate for defining the collaborative processes themselves, as well as the associated information to be shared. Then, the solution adopted was to develop an application that, taking like input to the system a PP order with a prefixed delivery date (DD) and amount of product, would be able to explore the space of solutions and providing then the most economic (if any) one to serve on time the required PP. In order to success with the application of the COM-EDM product, organisations involved had to share information about manufacturing plans, manufacturing stock levels, manufacturing capacity levels or distribution resources/availability. The basis of such an application is shown in Figure 3 and explained next.

(Figure 3)

A customer PP order, with a specific amount of products and PP delivery date (DD) for tiles and furniture, triggers the COM-EDM process. The application first checks whether the customer asks for installation or not. If so, the system should check what the earliest availability installation date is and to update the required PP delivery date, 
working out the new delivery date (DD'). Then, the application creates a list of feasible nodes from where the PP products are either manufactured or stored. With this information, a list of feasible routes from these potential nodes to the final delivery point is created. This is a ranked list that minimises associated distribution costs. The application checks now the DTP on the first ranked route (considering cotransportation issues between the involved value chains); if there is enough DTP to serve on time the product (DTP must be minor than the DD'), the application works out then the time left to obtain the products of the PP (new delivery date called DD'). It then checks if there is enough ATP to serve on time the product (meeting the DD') in the first node associated to the first ranked route (defined previously in the DTP checking). If yes, a confirmation message is sent to the user, booking this route and associated resources (DTP and ATP) up to 30 minutes for this particular PP order, waiting for the user to confirm it. In the case that there is not enough ATP, the system checks the CTP in this potential node associated to the first route; again, if there is enough CTP to meet the DD', the system communicates it to the user, who has to decide whether to confirm this order or not. In the case that the CTP does not accomplishes the required DD', the system checks now the second ranked route and so on. At the end, if the application does not find any feasible route that meets the stated PP order delivery date, it provides to the user with alternative feasible dates.

It is important to point out collaboration as the key issue in order to success within the meta- value chain context in general and in the COM-EPM product in particular. The COM-EDM process goes beyond a seller having access to order management information of different organisations and offering their products together. Collaboration must start by jointly defining what of their products are complementary and could, therefore, be sold conjointly. There are several issues such as aesthetic, physical or social factors that must be taken into account and customised for every targeted market. Then, each of the organisations needs to carry out this research and, once it is done, to bring it together and deciding all of them what products are susceptible of being complementary sold. Additionally, there is a considerably high amount of data to be shared by organisations, which exhorts to create and maintain collaboration at the meta-value chain level. For instance, if a customer order cannot be met, and it is a premium customer of one of the organisations of the meta-value chain, such an organisation will be able to check why the order cannot be met, and, if it is caused by other meta-value chain organisation, it will be able to negotiate in order to assure the accomplishment of the order. Further, another example could be the DTP, as the described application considers co- transportation processes between the involved organisations and associated value chains.

\subsection{Collaborative Forecasting Management (CFM)}

This product improves the forecasting by: (1) collecting information from all the relevant actors of the cross-value chain, (2) enhancing the forecasting algorithms, and (3) publishing the forecast results for their use in the whole cross-value chain. It enables to carry out a collaborative forecasting between the enterprises of the metavalue chain regarding product pack orders. This will lead to important cost shavings of the participants due to the collaborative information process established.

The ECOSELL meta-value chain was based on supply chains with an OEM configuration and, in particular, where the OEMs receive the demand information from several sales points. These sales points receive ECOSELL orders (from final 
customers that require a pack of products manufactured by several supply chains) and NO-ECOSELL orders (from final customers that require a product manufactured by a unique supply chain). In this situation, and taken the amount of information to manage and to share as the key factor, users decided to design a Single forecastingmultiple visibility process. In this scenario, the forecasting process is made only for the OEMs and each node of the supply chain know all the OEMs' and other nodes' demand forecasts and productions plans. The software used to carry out the CFM was DEMETRA 2.0, which is a Eurostat public usage one (Demetra, 2008).

The required information for this CFM model must come from the historic of demand of the OEM sale points: order code (for every order), order type (ECOSELL or not), client code, product code, requested quantity, delivery dates, selling point code, distribution model code.

\subsection{Collaborative Exception Management (CEM)}

This product provides collaborative means to define and capture, broadcast, and manage cross- value chain exceptions. Extended tracking \& tracing functionality support it. It enables enterprises to carry out a real time exception control and management programme. Then, if an exception comes up the system will alert, via SMS and/or email, to the adequate responsible people from the enterprises. Following a predefined flowchart a workflow, depending on the type of exception occurred (normal, important or critical), the system communicates it to the chosen person of the correspondent enterprise via email/SMS.

\subsection{Extended Performance Management (EPM)}

This product provides (1) a set of KPI (Key Performance Indicators) adapted to crossvalue chain performance management, and (2) a set of methods, techniques and tools to support the monitoring of these KPI, both internally and externally, and throughout the whole network. It carries out controlling and monitoring tasks regarding the performance of the meta-value chain in relation to the extended performance measurement system (PMS) defined by the members. All the members of the metavalue chain should define such an extended PMS and it should include all the main strategic objectives and associated KPIs. Then, organisations should feed these KPIs by putting periodically data in the database created to store meta-value chain performance data. Periodic revisions should take place to monitor and manage the defined extended PMS.

All the above-presented products have a collaborative nature, and therefore data interchange and sharing processes only will be fully achieved if the members of the meta-value chain do trust each other. This is not an easy task, as there are other issues to take into account such as equity, visibility and coherence (Rodriguez et al. 2007), (Hageback and Segerstedt, 2003), which might even interact between them and to have different intensity cycles over a period of time. However, enterprises that are forming a meta- value chain should be clear from the very beginning of not only the profits that such collaborative practices will bring to their organisations but also of the road to be followed and activities to deliver to achieve such advantages.

Generally speaking, real time communication and checking implies highly difficult data interchange and information sharing processes at the meta-value chain context. A customer at the end of the meta-value chain triggers the process when she orders a 
product-pack at the selling point. Then, the system should be able to check online different data from the enterprises forming the meta-value chain such as availability capacity, stock levels, planning data, etc. Additionally, the application should support the communication between enterprises to share information related to demand forecasting, performance management or work orders.

Figure 4 shows graphically both the main different informational flows that take place in this meta-value chain and the supportive architecture. Communication between modules, which are independent components, and with external systems was carried out exchanging XML files (IN or OUT flows), as observed in Figure 4. Besides, the shadow management acted as a filter in order to translate quantitative data into qualitative data according to user privileges.

(Figure 4)

In resume, the developed technological infrastructure offers the following functionalities:

- It allows integrations between separate supply chains: the infrastructure must support a distributed environment linking a cross-country network. All products need to be accessible to every user no matter their geographical location.

- It captures and sends data from multiple channels.

- It provides the multi-language possibility for all the products.

- It provides a workflow tool that allows managing tasks' flows for exceptions resolution and orders dispatching.

- It allows the evaluation of business rules in order to help to decide the workflow to execute in every specific case.

- It provides a global security level: authorization and authentication mechanisms are necessary in order to secure the execution of business processes.

- Log information must be stored for different business processes and transactions that could be, in some way, measured.

- Data interchange from multiple enterprises must be standardised (for instance, XML format) in order to be able to be understood for all actors in the network.

- Possibility of being able to integrate the products with any kind of enterprise's system.

- The products have been developed following a modular programming philosophy in order to be able to use each module independently. 
- User activities must be monitored in order to make a control and follow-up over user activities during the products execution.

\section{Application}

Both the toolset and the architecture above introduced have been applied, within the ECOSELL project, to a meta-value chain formed by the next three enterprises:

- A Spanish tiles manufacturer.

- An Italian glaze manufacturer.

- An Italian furniture manufacturer.

Two value chains form the meta-value chain: A Spanish tile manufacturer and its first tier supplier form one value chain whereas the Italian furniture manufacturer represents the other value chain. The tiles manufacturer has got three production plants and seven warehouses where its products can be stored. On the other hand, the Italian glaze manufacturer counts with two production plants and four warehouses. Finally, the furniture manufacturer has got one production plant and it counts with two warehouses. The application must take this into consideration specially when working out ATP/CTP/DTP issues.

The glaze manufacturer was a tiles manufacturer's first tier supplier, forming together one value chain. Such a value chain together with the Italian furniture manufacturer one constituted the meta-value chain whose main purpose for delivering and extended value proposition to final customers was to offer a product pack that included a combination of both tiles and furniture. The main results achieved as well as advantages and main drawbacks, coming from 6 months application of the different defined products, are next presented.

Regarding the application of the COM-EDM, the main advantages perceived by customers were the access to a truly extended value proposition; coordinated and synchronized delivery; disappearance of "Purchase Management" problems; higher degree of customization; lower total cost/time saving, understood as time saved by customers when aquiring different complementary products at once, including reliable delivery dates and perceiving therefore a higher service level. On the other hand, although the COM-EDM provided solutions that proved later to be feasible on more than a $90 \%$ of the times, some problems came up. The main problem was that the application, when dealing with products that could be taken from lots of different places in the network (19 in this particular meta-value chain), worked very slowly and even sometimes did not outcome feasible results. Additionally, and as a consequence of this problem, it would be logical to think that the simultaneous access to the application from different users could bring a problem of concurrency. At the data sharing level there were some problems related to the dynamicity of the data collection such as to keep booked for some time a certain amount of product and real time updated of manufacturing plans, manufacturing and transportation capacity. Most of these are technological based problems, which are still open issues to be improved. The design and application of a mathematical model that could govern the COM-EPM could perhaps deal more efficiently with the scenario when there are a big number of different locations to get the product from, although it would directly rely on computational requirements. 
At the value chain context, the application of the collaborative forecasting practices (CFM) between the tiles manufacturer and its first tier supplier, the glaze manufacturer. As stated above, such collaborative forecasting practices will enable forecasting data sharing between both manufacturers obtaining multiple competitive advantages such as cost optimisation minimising obsolescence risks ensuring that excessive amounts of stock are not produced; creation of collaborative environments supported by the implementation of ICT; or encouragement of collaborative decision making and negotiation processes. On the other hand, at the meta-value chain context, the main initial problem was the lack of data regarding product- pack orders when aiming to carry out the forecasting. Then, the adopted solution was to take the historical demand data from the individual products selected to be combined to constitute a product pack, and carry out a CFM that was visible to all the components of the meta-value chain. As the time were passing and real data from product pack demand orders could have gathered, they would be incorporated into the CFM system, replacing the initial one.

From a practical point of view, initially the biggest drawback of this product was to handle the numerous informational flows, as the informational requirements were high. Once that all the members of the meta-value chain contributed with the required information the CFM offered good results in terms of calculation of prevision and visibility to the involved parts.

The CEM achieved good working results from a functional point of view. In other words, when one of the defined exceptions came up the system, following the associated workflow, contacted the predefined people and decisions were made. However, the main problem associated to CEM was not a technological one but a conceptual one, as it was very difficult to reach a consensus about what an exception was and also if it was relevant enough for the meta-value chain for being included within the CEM. Further work on this area should be done when defining future exceptions for the meta-value chain.

Individual organisations defined an extended PMS, which had important strategic objectives related to the meta-value chain and product-pack offer such as "To improve market position", "To have a service level over the 90\%" or "To penetrate a new market". The main drawback with this product was the sharing of data between the members, as either it never came or there were delays. This might motivated because the organisations did take this product as the one that offered long-term results compared to the others that outcome results from the very first day. Emphasis should be put in the future to keep updated this product, as it is the core management tool of this meta-value chain and the one with the capabilities to monitor and control the evolution and achievements.

Based on the experience of this meta-value chain, the main recommendations for forming and maintaining a meta-value chain are the following:

- It is necessary that exist clear complementarities between the products or services to be commercialised as a package, in terms of functionality, pricing policies, market focusing, market strategies and design aspects.

- It is necessary to be in such a market situation that the customer is asking for integration of all the elements of the purchased package, and their associated services (design, installation, etc.). Market studies are recommended. 
- It is necessary that the companies that take part in the extended value proposition (EVP) given to the customer in the selling point do not pretend any step forward than collaboration (commercial, logistic, technical, etc).

- It is a situation considered as a real life requirement, the fact that each metavalue chain partner may have a different technical platform for their ICT systems in its own company and the meta-value chain technological platform has to adapt to his reality, mainly when each customer may ask for a different combination of companies in the product package that she is ordering. An especial attention has to be given to this aspect in order the meta-value chain technical solution do not interfere in each partner ICT infrastructure but complement, them adding value to each partner for collaboration.

- The different size of the companies taking part in the EVP must not be a limitation to the collaboration from business policy point of view, since it is not a constraint for the meta- value chain solution from methodological and technical point of view.

- The selling point commercial personnel must know perfectly the characteristics of the commercial, technical, production, and logistic principles and infrastructure of the collaborating companies, in order to perfectly understand the operative framework of the meta-value chain solution. Training must be given to this respect.

- One of the main barriers to success in the creation and maintenance of a metavalue chain might come from lack of trust between the members. Regular meetings and smooth communication between the parts are hercommendable to overcome this issue. It is necessary to apply equity, visibility and coherence to the decisions made. Further, and before to join/create a meta-value chain, the potential partners should carefully think of whether they are willing to share important data with other partners or not, as this is one of the key points in any collaborative process.

Additionally, the paper has met some of the research issues highlighted in the literature as presented previously in the introduction. Then, this work has followed an integral approach that aims to cover all the main business processes at the meta-value chain context: Collaborative forecasting management, collaborative order management, extended distribution management, collaborative exception management and extended performance management. Moreover, it has provided the basis to form and maintain a meta-value chain able to implement a meta-value chain strategy.

Finally, it is possible to affirm that, as a conclusion, the organizations from the presented meta- value chain have reached some important competitive advantages such as selling chain visibility, as they can access other customers that had not traditionally been a target; higher degree of flexibility; competitive advantage; seamless integration and coordination; collaboration practices; better market knowledge; and resource and network optimization. 


\section{Conclusions and future research}

This paper has presented a new competitive strategy through collaborative practices: The meta- value chain. Enterprises willing to create a meta-value chain need to carry out sound analyses and assessment as well as to create tools not only at the business level but also at the IT one. From these analyses the main processes to be covered both methodologically and technologically will come up. Then, once the products to be developed have been defined enterprises should define the supporting technological toolset and architecture. Needed informational and products/services flows between the enterprises must be clearly defined and data provided without delays. This case study has presented five different products - collaborative order management; extended distribution management; collaborative forecasting management; extended performance management and collaborative exception management- as well as their main results. Practical results indicate that enterprises forming a meta-value chain have a strategic tool that mainly allows them to offer more customised products, to have a better market knowledge, competitive advantages and resource and network optimisation. On the account of the main barriers to achieve a meta-value chain successful implementation are issues such as data sharing, trust, coherence, visibility and equity, which are all difficult to overcome and must be carefully watched. Therefore, organisations should focus on preventing them from the beginning of the collaborative relationships. Besides, technological problems might come up in terms of concurrency and computational times, so analyst should think of other alternative ways of implementing the presented products.

\section{Acknowledgements}

This work has been developed in the framework of a project partially funded by the European Union, titled 'Extended Collaborative Selling Chain (ECOSELL)'. Ref. GRD1-2001-40692. 


\section{References}

Alfaro, JJ., Ortiz, A., Rodriguez, R.R., 2007. Performance measurement system for enterprise networks. International Journal of Productivity and Performance Management, Vol 56, 305-334.

Akkermans, H., Bogerd, P., Doremalen, J., 2004. Travail, transparency and trust: A case study of computer-supported collaborative supply chain planning in high-tech electronics. European Journal of Operational Research, Vol 153, Issue 2, 445461.

Bititci, U. S., Mendibil, K., Martinez, V., Albores, P., 2005. Measuring and managing performance in extended enterprises. International Journal of Operations \& Production Management, Vol 25, 333-353.

Busi, M. and Bititci, U.S., 2006. Collaborative performance management: present gaps and future research. International Journal of Productivity and Performance Management, Vol 55, Issue 1, 7-25.

Christopher, M., 2003. Logistics and Supply Chain Management. 3rd ed. New York: Prentice Hall.

Cingil, I. and Dogac, A., 2001. An architecture for supply chain integration and automation on the Internet. Distributed and parallel databases, Vol 1, 59-102.

Cohen, S. and Roussel, J., 2003. Strategic Supply Chain Management: The 5 disciplines for top performance. McGraw-Hill: New York.

Coughlan, P. and Coughlan, D., 2002. Action research: action research for operations management, International Journal of Operation and Productions Management, Vol 22, Issue 2, 220-240.

Deek, F., Defranco, J., McHugh, J., 2003. A model for collaborative technologies in manufacturing. International Journal of Computer Integrated Manufacturing, Vol 16, Issue 4, $357-371$.

Demetra 2.0. Eurostat. Available from: http://http://circa.europa.eu/irc/dsis/eurosam/info/data/demetra.htm [Accessed: 25 April 2008]

Derrouiche, R., Neubertl, G., Bouras, A., 2008. Supply chain management: a framework to characterize the collaborative strategies. International Journal of Computer Integrated Manufacturing, Vol 21, Issue 4, 426 - 439.

Fairchild, A., 2005. Intelligent matching: integrating efficiencies in the financial supply chain. Supply Chain Management: An International Journal, Vol 10, Issue 3-4, 244-248.

Gunasekaran, A., Laib, K., Cheng, T.C.E., 2008. Responsive supply chain: A competitive strategy in a networked economy. Omega, Vol 36, 549-564. 
Hageback, C., Segerstedt A., 2003. The need for co-distribution in rural areas - a study of Pajala in Sweden. International Journal of Production Economics, Vol 89, 153-163.

Kasanen, E., Lukka, K., Siitonen, A., 1993. The constructive approach in management accounting research, Journal of Management Accounting Research, Vol 5, 243-264.

Ketchen, D.J.and Hult, G.T.M., 2007. Bridging organization theory and supply chain management: The case of best value supply chains. Journal of Operations Management, Vol 25, Issue 2, 573-580.

Kim, T.J., Lee, S., Kim, K., Kim, C.H., 2006. A modeling framework for agile and interoperable virtual enterprises. Computers in industry, Vol. 57, 204-217.

Lee, W.B., Cheung, H.C.W., Choy, L., Choy, K.L., 2003. Development of a webbased enterprise collaborative platform for networked enterprises. Business Process Management Journal, Vol 9, 1, 46-58.

Molina, A., Aca, J., Wright, P., 2005. Global collaborative engineering environment for integrated product development. International Journal of Computer Integrated Manufacturing, Vol 18, Issue 8, 635 - 651.

Pappas, M., Karabatsou, V., Mavrikios, D., Chryssolouris, G., 2006. Development of a web-based collaboration platform for manufacturing product and process design evaluation using virtual reality techniques. International Journal of Computer Integrated Manufacturing, Vol 19, Issue 8, 805 - 814.

Petersen, K.J., Ragatz, G.L., Monczka, R.M., 2005. An Examination of Collaborative Planning Effectiveness and Supply Chain Performance, The Journal of Supply Chain Management, Vol 41, Issue 2, 14-25.

Prasad, S. and Sounderpandian, L., 2003. Factors influencing global supply chain efficiency: implications for information systems. Supply Chain Management: An International Journal, Vol 8, Issue 3-4, 241-250.

Putnik, G.D. and Cunha, M.M., 2007. Knowledge and Technology Management in Virtual Organizations: Issues, Trends, Opportunities and Solutions. IGI Publishing. (ebook).

Raghunathan, S., 1999. Interorganizational collaborative forecasting and replenishment systems and supply chain implications. Decision Sciences, Vol 30, Issue 4, 1053-1071.

Rodriguez, R.R., Gomez, P, Franco, D., Ortiz, A., 2007. Establishing and keeping inter- organisational collaboration: Some lessons learned. International Federation for information Processing, Vol 1, 214-222.

Rupp, T.M. and Ristic, M., 2004. Determination and exchange of supply information for co- operation in complex production networks. Robotics and Autonomous Systems, Vol 49, Issue 3-4, 181- 191. 
Seuring, S.A., 2006. Supply chain controlling: summarizing recent developments in German literature. Supply Chain Management: An International Journal, Vol 11 Issue 1, 10-14.

Shang, H., Zhao, Z., Thorn, R., 2003. Implementing Manufacturing Message Specifications (MMS) within collaborative virtual environments over the Internet. International Journal of Computer Integrated Manufacturing, Vol 16, Issue 2, 112 $-127$.

Sohn, S.Y. and Lim, M., 2008. The effect of forecasting and information sharing in SCM for multi-generation products. European Journal of Operational Research, Vol. 186, Issue 1, 276-287. 


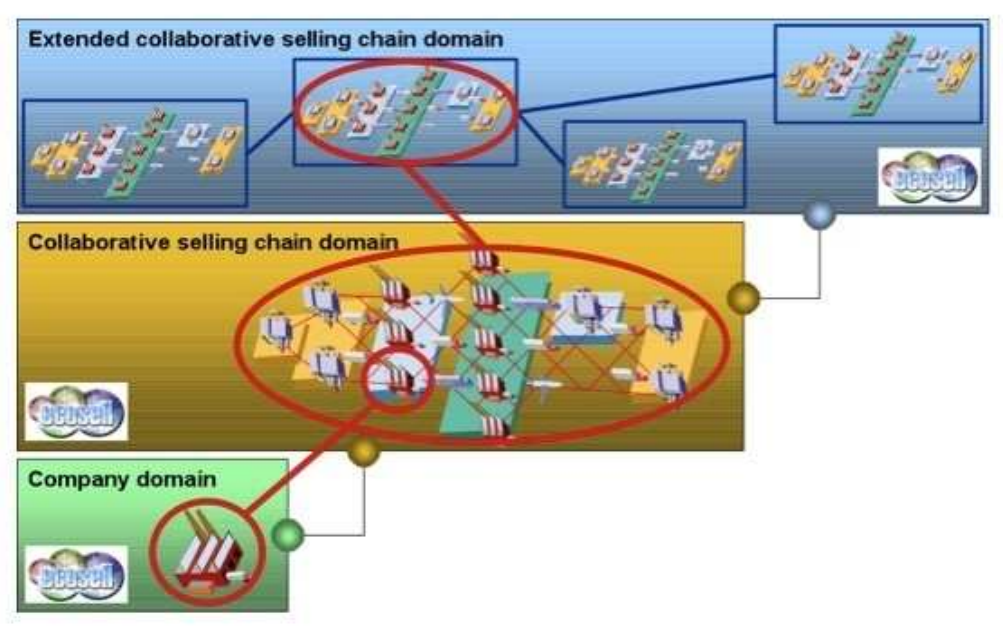

Figure 1. Business levels

Figure 1 Business levels $254 \times 190 \mathrm{~mm}(72 \times 72$ DPI $)$ 


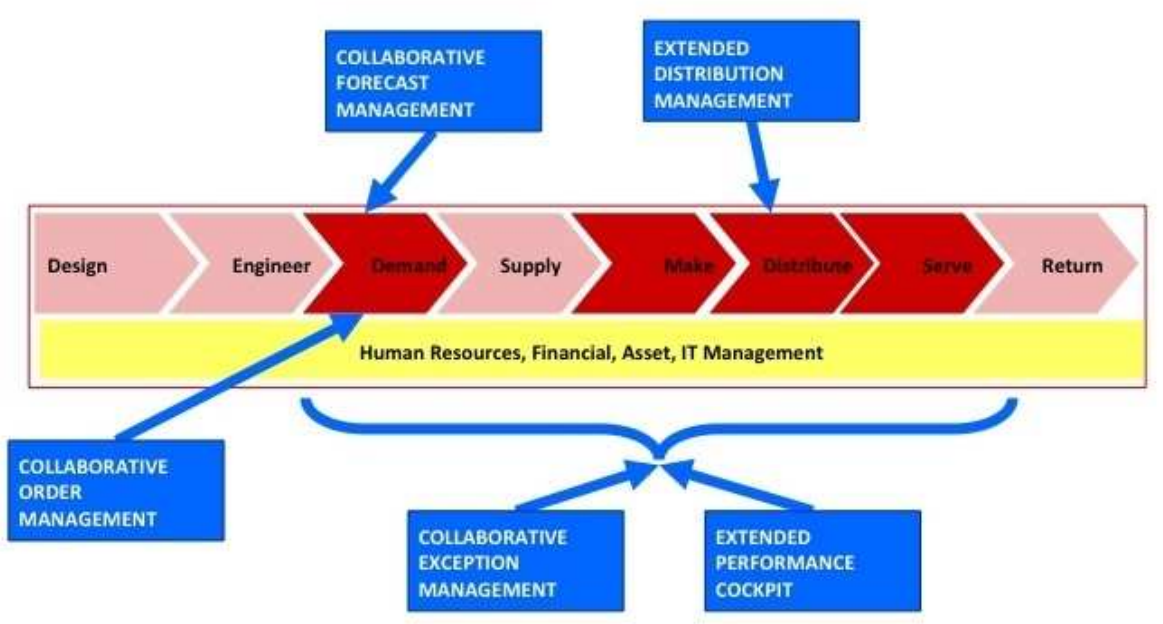

Figure 2. Meta-value chain main processes

Figure 2 Meta value chain main processes $254 \times 190 \mathrm{~mm}(72 \times 72 \mathrm{DPI})$ 


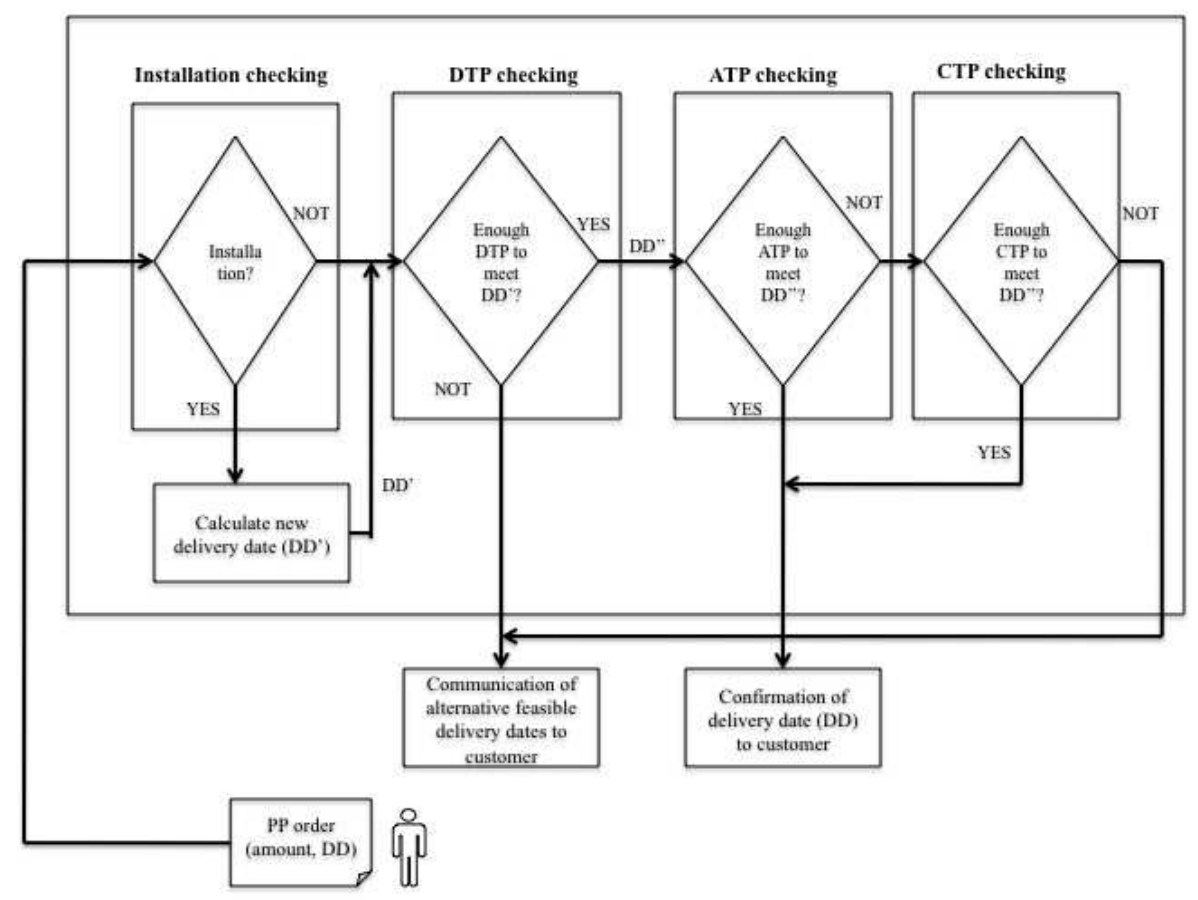

Figure 3. COM-EDM application

Figure 3 COM EDM application $254 \times 190 \mathrm{~mm}(72 \times 72 \mathrm{DPI})$ 


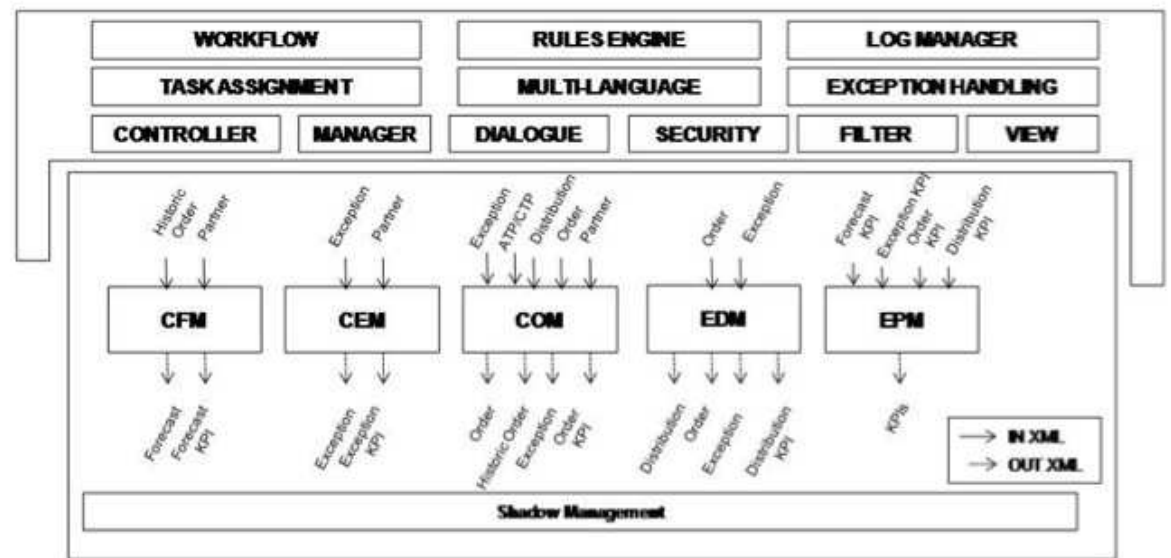

Figure 4. Technological infrastructure of the meta-value chain

Figure 4 Technological infrastructure of the meta value chain $254 \times 190 \mathrm{~mm}(72 \times 72 \mathrm{DPI})$ 